\title{
How do people choose their doctor?
}

\author{
Christopher J Salisbury
}

\begin{abstract}
The white paper Working for Patients assumes that patients choose general practitioners on the basis of the service that they provide and that increased competition among doctors will raise standards. To investigate these assumptions a postal questionnaire survey was carried out of 447 people who had recently registered with a new general practitioner. The results disclosed a remarkable lack of consumerist behaviour. Most people registered with their nearest doctor, and many did not register until they were already ill. Many people knew nothing about their new practice but seemed unworried by this and showed little inclination to seek information.

These findings suggest that competition among general practitioners is unlikely in itself to raise standards of care.
\end{abstract}

\section{Introduction}

The government has recently published white papers on primary health care and the future management of the National Health Service. ${ }^{\prime 2}$ One impetus for the proposed changes has been a desire to see the philosophy of consumerism and competition applied to general practice. It is widely believed that people have difficulty finding out about doctors and therefore have little effective choice when they need a new general practitioner. The government intends to make more information about general practices available, loosen restrictions on advertising, and make it easier for patients to choose and change doctors. This approach is linked to the assumption that increased competition and a structure of capitation weighted payments will lead to a raising of standards, as doctors have to provide services that people want.

There has been argument about how relevant these issues of consumerism are within the present NHS structure. ${ }^{3}$ It cannot be assumed that competition to attract new patients will necessarily have the effects that the government wishes. ${ }^{4}$ It is not known what influences a new patient to choose a particular medical practice, how patients attempt to find out about doctors, or what they wish to know. The little evidence available suggests that most people change doctors only when they move house and that they then tend to register with the nearest practice. ${ }^{5-7}$ Most of the published research, however, is several years old, and consumer attitudes have changed dramatically. The previous evidence comes from a few questions asked within large social surveys not directly concerned with choosing a doctor, and people were often being asked about a choice that they had made many years before. No study has apparently questioned people at the time of registration with a new doctor. This information is crucial to inform the debate about the proposed changes in the health service and may also become important to doctors having to compete for patients. This study considers how people find out about their doctors, why they change practices, and what factors influence their choice of general practitioner.

\section{Subjects and methods}

Details were recorded of all patients registering with five general practices in Reading during eight weeks between January and March 1989. These practices serve overlapping areas which include a social mixture of inner city terraces, middle class suburban districts, and council housing estates. People in these areas have a wide choice of local doctors, three of the five practices being within $1.5 \mathrm{~km}$ (1 mile) of each other. The practices are varied in terms of size, type of building, training status, and the doctors' age, sex, and ethnic origin.

A postal questionnaire was sent to each patient or to the person who brought in the medical cards when a family or group registered together at the same address. The questionnaires were sent in the name of West Berkshire Community Health Council with a covering letter and included both open and closed questions about the person's choice of doctor. The questions mainly concerned how the person had obtained information about doctors and how he or she made a choice in reality rather than asking about theoretical opinions. Standard demographic details were obtained about the respondents. The patients' addresses were plotted on a map to determine their nearest practice.

A reminder was sent to non-respondents after two weeks and a shorter questionnaire sent after a further three weeks. The questionnaires had been developed after personal interviews and then a methodological pilot. This confirmed that postal questionnaires provided adequate information compared with telephone interviews with newly registering patients. The final questionnaire was modified and fully piloted.

The $\chi^{2}$ test was used to analyse the results. Numbers of patients do not always equal the total response because some people did not answer every question.

This paper summarises the main findings of the survey. Further analysis is planned of how patients' choices were influenced by their age, sex, social class, and ethnic group.

\section{Results}

During the study period 791 people registered with the five practices. These individual patients and families were represented by 447 people to whom questionnaires were sent, of whom $323(72 \%)$ replied. Thirty two of the replies were shorter reminder questionnaires, so that the available response for some questions was 291 $(65 \%)$. Respondents and non-respondents were closely matched in age distribution (average ages 28.6 and 28.3 years respectively) but not sex; $168(52 \%)$ responders and $50(40 \%)$ non-responders were women $\left(\chi^{2}=4 \cdot 44\right.$; $\mathrm{df}=1 ; \dot{\mathrm{p}}<0.05))$. The social class distribution of the sample was similar to that of England and Wales.

Table I shows that the main reason for choosing a
Oxford Road, Reading RG3 1HG.

BrMed F 1989;299:608-10 
TABLE I-Responses to question, "What was the main reason that you chose the practice that you've registered with?"

\begin{tabular}{lr}
\hline & $\begin{array}{r}\text { No (\%) of } \\
\text { responses }\end{array}$ \\
\hline It was the nearest to your home & $136(44)$ \\
It was recommended by someone & $72(23)$ \\
It was the only practice you knew about & $12(4)$ \\
You compared several practices and this seemed the best & $13(4)$ \\
It was the only practice able to accept you & $7(2)$ \\
Others in your family or house were already registered there & $50(16)$ \\
Because this practice had a woman doctor & $5(2)$ \\
Other reason & $15(5)$ \\
\hline All responders & 310 \\
\hline
\end{tabular}

practice was that it was the nearest. Most people (187/ $322 ; 58 \%$ ) believed that they registered with their nearest practice, but in fact only $42 \%$ (137/323) actually registered with the nearest doctor on the map. More than four fifths of respondents changed doctors because they had moved to the area and only $5 \%(16 /$ 313 ) because they were dissatisfied with their previous doctor (table II). Some 71\% (207/290) of respondents

TABLE II-Responses to question, "Why are you changing your doctor?”

\begin{tabular}{lr}
\hline & $\begin{array}{r}\text { No(\%) of } \\
\text { responses }\end{array}$ \\
\hline You've moved to the area & $260(83)$ \\
$3(1)$ \\
Your last doctor moved or died or retired & $16(5)$ \\
This surgery is more convenient & $16(5)$ \\
You were not satisfied with your last doctor & $18 \quad(6)$ \\
Other reason & 313 \\
\hline All responders & \\
\hline
\end{tabular}

joined a practice within $1.5 \mathrm{~km}$ of their homes and most $(190 / 299 ; 64 \%)$ would normally get to the surgery on foot. Roughly a quarter $(80 / 299 ; 27 \%)$ would travel by $\mathrm{car}$, and the remainder were housebound or used other means.

Of those who chose a new doctor after moving house, only $58 \%(148 / 256)$ had registered within four months and $18 \%(45 / 256)$ waited more than one year. Almost half $(134 / 285 ; 47 \%)$ of the patients were ill when they registered; this was not related to how long it took them to register or whether they went to the nearest practice.

A third of the sample $(119 / 313 ; 38 \%)$ knew of only one practice at the time that they registered. Eighty nine people (28\%) knew of one other practice and 105 (34\%) knew of at least two others. Table III shows that half $(149 / 314 ; 47 \%)$ of the patients first heard of the practice from a friend, neighbour, or relative, and a third $(105 / 314 ; 33 \%)$ had first seen the surgery building. Table IV shows how people tried to find out about the practice before they joined, and in particular that $40 \%$ $(127 / 320)$ knew nothing about the practice. When asked how many people they had spoken to about choosing a practice $40 \%(114 / 287)$ of the sample indicated that they had not spoken to anyone.

By using a four point ordinal scale patients rated

TABLE III-Responses to question, "Thinking of the practice that you chose to join, How did you first know that the practice existed?"

\begin{tabular}{lr}
\hline & $\begin{array}{r}\text { No (\%) of } \\
\text { responses }\end{array}$ \\
\hline You had seen the surgery building & $105(33)$ \\
A friend, neighbour, or relative told you about the practice & $149(47)$ \\
You got the address from the telephone book & $18(6)$ \\
You looked in the medical list at a library & $2(1)$ \\
You asked the family practitioner committee & $8(3)$ \\
You asked the community health council & 0 \\
Other & $32(10)$ \\
\hline All responders & 314
\end{tabular}

which things were most important to them in choosing a new doctor. Table $\mathrm{V}$ gives the results ranked in order of importance. More women $(52 / 164 ; 32 \%)$ than men $(21 / 152 ; 14 \%)$ thought that having a woman doctor was essential or very important $\left(\chi^{2}=13 \cdot 23 ; \mathrm{df}=1 ; \mathrm{p}<0 \cdot 001\right)$, but even for women this factor did not seem particularly important.

Most people (228/307; 74\%) thought that it was easy or fairly easy to find out about doctors' practices before they registered, and a quarter $(79 / 307 ; 26 \%)$ thought that it was difficult or fairly difficult. Only $8 \%(24 / 289)$

TABLE IV-Responses to question, "Did you try to find out anything about the practice before you registered? If so, how? Please tick as many boxes as apply"

No (\%) of responses

By asking people who previously lived in your house or flat about the practice

about the practice

g neighbours about the practice

By asking friends or workmates about the practice

By asking your family about the practice

By asking your previous doctor about the practice

By visiting the surgery and asking questions

You didn't know anything about the practice

Other

All responders

320

* Some people gave more than one response.

of the sample had seen a practice leaflet, even though several of the relevant practices made them available. A small majority $(153 / 286 ; 53 \%)$ of respondents thought that NHS family doctors should be allowed to advertise, $19 \%(55 / 286)$ said that they should not, and $27 \%(78 /$ 286) were undecided.

Only $29 \%(84 / 288)$ of patients had asked to register with a particular doctor. This rose to $45 \%(28 / 62)$ when the practice had been recommended and to half $(22 / 44)$ when others in the family were already registered there. Overall, people seemed to choose a practice rather than a doctor.

\section{Discussion}

The government intends to "reward General Practitioners whose services attract more patients,"2 which implies that people choose their doctor on the basis of the services that he or she provides. In a recent review Leavey et al showed that this consumerist approach to medicine depends on several premises. ${ }^{3}$ These include a motivation on the part of patients to exercise choice, a range of alternatives from which to choose, and information about those alternatives.

My findings show a remarkable lack of consumerist behaviour in the way that people choose their doctor. Most patients $(205 / 310 ; 66 \%)$ exercised little active choice, in that either they went to the nearest doctor or to one at which other family members were already registered or they went to the only practice they knew of which was able to accept them. Most people changed doctors only because they had moved, which corresponds with earlier findings that few people seriously, contemplate changing their doctor for any other reason. ${ }^{56}$ Market forces depend for their effect on people changing practices to obtain a better service, but only one tenth of new patients (32/313) seemed to have done this.

The apparent lack of motivation by patients to exercise choice was not due to a shortage of alternatives. All patients in this survey had a wide choice of doctors within a short distance, and two thirds of the respondents knew of more than one surgery. That most people do not seem actively to choose their doctors may be because it is difficult to find out about different practices. ${ }^{8}$ More than a third of the sample knew 
TABLE $\mathrm{V}-$ Responses to question, "What things are most important to you in choosing a doctor? The following question gives a list of things which are important to some people." (Percentages given in parentheses) ${ }^{\star}$

\begin{tabular}{|c|c|c|c|c|c|}
\hline & Essential & $\begin{array}{c}\text { Very } \\
\text { important }\end{array}$ & $\begin{array}{c}\text { Fairly } \\
\text { important }\end{array}$ & $\begin{array}{c}\text { Not } \\
\text { important }\end{array}$ & $\begin{array}{c}\text { All } \\
\text { responders }\end{array}$ \\
\hline \multicolumn{6}{|l|}{ Having a doctor who is friendly and easy to } \\
\hline Convenient surgery hours & $143(45)$ & $133(42)$ & 37 (12) & $3(1)$ & 316 \\
\hline Being able to get an appointment on the day & & & & & \\
\hline you wish & $98(31)$ & $144(45)$ & $74(23)$ & $1(0)$ & 317 \\
\hline Having pleasant, helpful receptionists & $72(23)$ & $159(50)$ & $79(25)$ & $6(2)$ & 316 \\
\hline Having an appointments system & $99(32)$ & $114(36)$ & $72(23)$ & $28(9)$ & 313 \\
\hline $\begin{array}{l}\text { A practice which runs prevention and screening } \\
\text { programmes }\end{array}$ & $91(29)$ & $122(39)$ & $75(24)$ & $27(9)$ & 315 \\
\hline Having a doctor who is very good with children & $82(26)$ & $99(32)$ & $57(18)$ & $76(24)$ & 314 \\
\hline Being on a good bus route & $34(11)$ & $86(27)$ & $84(27)$ & $112(35)$ & 316 \\
\hline Being able to see a woman doctor & $27(9)$ & $46(15)$ & $79(25)$ & $164(52)$ & 316 \\
\hline Having a smart, modern surgery building & $17(5)$ & $54(17)$ & $161(51)$ & $83(26)$ & 315 \\
\hline Having a carpark & $22(7)$ & $48(15)$ & $91(29)$ & $154(49)$ & 315 \\
\hline $\begin{array}{l}\text { Having a doctor who is the same nationality } \\
\text { as you }\end{array}$ & $31(10)$ & $30(10)$ & $52(17)$ & $201(64)$ & 314 \\
\hline
\end{tabular}

^Factors are ranked by proportion of respondents designating them "essential" or "very important."

nothing about the practice that they registered with, yet three quarters of the respondents said that it was easy to find out about doctors. People showed little inclination to use the sources of information that are currently available. Very few had contacted the family practitioner committee or community health council or had read practice leaflets. These results suggest that most people are not demanding more information before choosing a doctor.

Alternatively, it may be that the information available is not what patients wish to know. It seems that a doctor's approachability and manner are easily the most important things that patients look for in a general practitioner, and this sort of information may be hard to obtain. At present patients largely rely on personal recommendation and inquiry. Providing more detailed written information, as proposed, will not help patients decide about the intangible qualities of a doctor. Written material will inevitably concentrate on organisational matters.

In 1981 Ritchie et al reported that very few people were interested in details of practice organisation. ${ }^{5}$ By contrast, this survey shows that some people do attach importance to availability of appointments and surgery opening hours. Competition among doctors may well lead to more extended opening hours but whether it will lead to a raising of other standards is debatable. Buckley raised the "unfashionably paternalistic" possibility that responding to "patients' demands rather than needs" may actually harm some aspects of the service-for example, health promotion. ${ }^{+}$

We may speculate that people are not demanding in their choice of doctor because they do not expect to have much need of a general practitioner or do not wish to think about doctors until they are ill. This is supported by the finding that many people did not register until several months after moving and then actually needed a doctor at the time. In this way choosing a doctor may be less analogous to the consumer's choice of a new car but more like finding a local garage quickly when the car breaks down.

The lack of discriminating consumer choice shown by this research might be said to undermine the assumptions of the white paper, which depend on the power of market forces in primary health care. Alternatively, however, the results might be used to illustrate the need for the public to become far more discriminating in their choice of doctors and thus justify some of the radical changes proposed.

This study was supported by West Berkshire Community Health Council and the Berkshire Family Practitioner Committee and was conducted as part of an MSc degree at London University. The MSc course fees were partly funded by Upjohn Pharmaceuticals. I thank my supervisor, Nicky Britten, my research assistant, Jane Graham, and the receptionists of the practices concerned.

1 Secretaries of State for Health, Wales, Northern Ireland, and Scotland. Promoting better health: the government's programme for improving primary healt care. London: HMSO, 1987. (Cmnd 249.)

2 Secretaries of State for Health, Wales, Northern Ireland, and Scotland. Working for patients. London: HMSO, 1989. (Cmnd 555.)

3 Leavey $\bar{R}$, Wilkin D, Metcalfe D. Consumerism and general practice. Br Med $\mathcal{J}$ 1989;298:737-9.

4 Buckley E. Working for patients-a journey into the unknown. $f(R$ Coll $G e$ Pract 1989;39:87-90.

5 Ritchie J, Jacoby A, Bone M. Access to primary health care. London: HMSO,

6 Simpson R. Áccess to primary care. London: HMSO, 1979. (Royal Commissio on the NHS/National Consumer Council research paper No 6.)

7 Prescott-Clarke P, Brooks T, Mackray C. Focus on health care. Surveying the public in four health districts. London: Social and Community Plannin Research, Royal Institute of Public Administration, 1988 8 Anonymous. Finding a doctor: too much of a lottery. $\mathrm{Br}$ Med $\mathcal{Y}$ 1989;298:466.

(Accepted 11 fuly 1989)

\section{MATERIA PARAMEDICA}

\section{Rapid assessment of character: how to do it}

After my retirement from wholetime hospital practice I joined the panel of medical examiners at the BUPA medical centre at King's Cross in central London. We enjoyed working under the firm but paternal administration of Dr Hugh Pentney, the former clinical director. Clients (or "patients," as he preferred to call them) attended for general health screening. After submitting to a battery of tests and answering a questionnaire they were ushered into the consulting room. History taking was guided by a proforma, which covered all aspects of health and lifestyle that might be relevant to the discovery of occult disease or future ill health. Clients came from all walks of life, but most were senior business executives, from whom I obtained a glimpse of the hitherto unknown world of commerce. The proforma was merely a guide; the examining doctor was free to inquire into any past experience, or to expand any item.

When it came to the client's education, I would inquire about the type of school and whether he was a boarder. I found that those who had been boarders at a public school ${ }^{\star}$ were identifiable within a couple of minutes by their bearing. This aroused my curiosify. I accordingly made a note, shortly after the client entered the consulting room, of my guess as to his type of schooling - namely, day boy living at home or boarder at a public school. In 100 consecutive cases I was in error once and correct 99 times, with nil "don't knows." I find it almost impossible to put in words that distinctive but indefinable demeanour of the ex public schoolboy. Perhaps more resolute, forthright, and, at least on the surface, more self confident? I don't know the answer. In any case, although the capacity to differentiate must surely indicate the pyschological effects of the client's early training, it is a useless talent.

Far more useful is the capacity to assess character when interviewing candidates for a job. In this respect I score nought out of 10 . Yet there are those well endowed with this important talent - for I firmly believe that it is a talent, though training and experience may help a little. Some decades ago I sat on a committee to select a medical registrar. Also on the committee was David Pyke, who had recently been appointed as consultant diabetologist (though I doubt that the term had then been coined). One candidate was, with a single exception, universally liked. He was urbane, unflustered, well dressed but not oversmart. A large majority vote ensured his appointment. Whereupon David Pyke rather to everyone's surprise said, "I think we have done a grave disservice to this young man. He will not be promoted during his two years; he will fail his membership [MRCP examination], and he will go into general practice." We would, in effect be wasting the candidate's time. What David Pyke predicted is exactly what happened. A most useful gift, if you have it.- BERNARD J FREEDMAN

"American readers should note that the term "public school" refers to the most expensive type of private school. 